J. Dairy Sci. 92:4135-4145

doi:10.3168/jds.2009-2070

(c) American Dairy Science Association, 2009.

\title{
The characterization of the physicochemical and sensory properties of full-fat, reduced-fat, and low-fat ovine and bovine Halloumi ${ }^{1}$
}

\author{
L. Lteif, A. Olabi, ${ }^{2}$ O. Kebbe Baghdadi, and I. Toufeili \\ Nutrition and Food Science Department, American University of Beirut, Riad El Solh 1107 2020, Beirut, Lebanon
}

\begin{abstract}
Halloumi cheese is a popular cheese in Lebanon and the Middle East. Today, health-conscious consumers are demanding lower fat foods with sensory properties that are comparable to their full-fat counterparts. The objectives of this work were to characterize the physicochemical and sensory properties of bovine and ovine Halloumi of different fat levels and to provide a baseline sensory profile for Halloumi cheese. Full-fat, reduced-fat, and low-fat samples were produced from ovine and bovine milks in 2 batches resulting in a total of 12 batches. The fat, protein, moisture, ash, $\mathrm{pH}$, sodium, and calcium levels were determined and the instrumental textural characteristics of the samples were measured using a texture analyzer. Eleven trained panelists used quantitative descriptive analysis to profile the sensory attributes of the samples and an acceptability test was conducted with 84 panelists. The type of milk (ovine vs. bovine) significantly affected the moisture and protein contents, whereas fat level had a significant effect on moisture, fat, protein, and ash contents. Instrumental texture analysis revealed that the type of milk significantly affected adhesiveness, chewiness, and hardness, whereas the fat level affected chewiness, hardness, adhesiveness, and cohesiveness. The sensory results of the trained panelists revealed that the ovine cheese was more yellow and harder than bovine cheese, whereas bovine cheese was squeakier. Low-fat and reduced-fat cheeses were also more yellow and harder than full-fat cheese, and full-fat cheese was more moist with no significant differences between the low-fat and reduced-fat varieties. Type of milk and fat level did not have any significant effect on fermented flavor, whey flavor, or saltiness. Bovine cheese received significantly higher scores on overall acceptability, texture acceptability, and significantly lower scores on the
\end{abstract}

Received January 23, 2009.

Accepted May 12, 2009.

${ }^{1}$ Use of names, names of ingredients, and identification of specific models of equipment is for scientific clarity and does not constitute any endorsement of product by authors, the Nutrition and Food Science Department, or the American University of Beirut.

${ }^{2}$ Corresponding author: ammar.olabi@aub.edu.lb food action rating scale. Full-fat cheese obtained the highest score on overall acceptability, and texture acceptability decreased significantly with decreasing fat levels.

Key words: Halloumi cheese, bovine milk, ovine milk, sensory properties

\section{INTRODUCTION}

Halloumi cheese is the traditional cheese of Cyprus, and is very popular in countries such as Lebanon, Jordan, and Turkey. Production and exports of Halloumi cheese have increased considerably in Cyprus, where it is considered the main cheese in terms of its popularity and contribution to agricultural exports. Halloumi cheese production increased from 4,730 tonnes in 1999 to 6,600 tonnes in 2002 (Gibbs and Morphitou, 2004) and the Halloumi cheese market is expected to grow further in the coming years (Papademas, 2006).

Halloumi cheese is a semi-hard to hard unripened cheese and has no obvious skin or rind. Its texture is compact and unyielding to applied pressure. Halloumi cheese is elastic and compact with no holes. If holes are present they are usually scarce and irregular. The cheese can be easily sliced into generous portions. The color varies from white when ovine or caprine milk is used to yellowish when bovine milk is the main ingredient. Upon heating, the texture is similar to that of the raw cheese but the stretch and melt properties are altered: the sliced cheese melts evenly, has the capacity to stretch but is not tough or chewy, and behaves like a concentrated viscoelastic polymer solution when molten (Lelievre et al., 1990; Robinson, 1991; Papademas and Robinson, 1998).

Fresh Halloumi cheese is consumed directly after manufacture. Fresh Halloumi cheese has a distinct aroma and a mild milky and creamy flavor. On the other hand, mature Halloumi cheese is matured for at least $40 \mathrm{~d}$ after production before being introduced to the market. Alterations in the texture and flavor of the cheese take place during maturation (Papademas, 2006).

Traditionally, Halloumi cheese was produced from raw ovine or caprine milks, alone or as blends. However, 
because of the growing market demand, new regulations were created to permit the use of bovine milk if the origin of the cheese milk is declared on the label of the product (Moatsou et al., 2004). Halloumi cheese has a unique flavor and taste and a connoisseur can easily distinguish Halloumi made from different milk mixtures (Papademas, 2006). However, these unique sensory characteristics are more pronounced in the matured cheese compared with fresh cheese (Papademas and Robinson, 2000). The manufacturing of Halloumi cheese has been described previously (Papademas, 2006).

According to the Cypriot Standards (Papademas et al., 2000), Halloumi cheese should contain a maximum of $3 \%$ sodium chloride, have a minimum fat in dry matter content of $43 \%$, and a maximum moisture content of $46 \%$. However, these figures apply mainly to traditional Halloumi cheese produced from ovine and caprine milks and studies have shown that Halloumi cheese produced from bovine milk can have a different chemical composition (Papademas et al., 2000). Several studies have revealed changes in the cheese composition between cheeses produced from bovine versus ovine and caprine milks (Papademas and Robinson, 2000; Milci et al., 2005). Moreover, several studies have compared the acceptance of Halloumi cheese produced from bovine, ovine, or caprine milk (Kaminarides et al., 2000; Papademas and Robinson, 2000, 2001; Milci et al., 2005). Papademas and Robinson (1998) believed the transition toward bovine milk had an impact on the sensory quality of Halloumi cheese, because the "old" aroma and flavor had been lost.

Consumption of saturated fat has been shown to be highly correlated with an increased risk for obesity, atherosclerosis, coronary artery disease, and elevated blood pressure (Watts et al., 1996; Van Horn and Ernest, 2002). This has created an increased consumer awareness and increase in the demand for and supply of low-fat foods including cheese (Sloan, 2001; Kavas et al., 2004). The production of low-fat cheese has been regulated by many agencies (Shank and Carson, 1990). In Cyprus, 2 categories of low-fat cheese have been recognized: less-fat cheese containing $25 \%$ less fat than the regular cheese and reduced-fat cheese containing $50 \%$ less fat than the regular cheese (Papademas et al., 2000; Punidadas et al., 2000). In a similar manner to the type of milk differences, compositional differences were obtained for full-fat, less-fat, and reduced-fat Halloumi cheese produced from bovine milk (Papademas et al., 2000).

Papademas et al. (2000) found that the increase in protein content affected some of the basic properties of Halloumi cheese such as chewiness and hardness. Textural analysis showed that low-fat and reduced-fat samples were significantly harder and chewier than the full-fat samples. Protein content also affected the fracturability of the samples, as fracturability was significantly lower in the full-fat cheese. Other studies have demonstrated the effect of Halloumi's fat content on the textural properties of the cheese (Theophilou and Wilbey, 2007). The sensory evaluation scores obtained from their study showed a significant difference in the overall preference for the full-fat, low-fat, and reducedfat bovine Halloumi cheese. Preference increased as fat in dry matter increased and decreased as protein content increased. Therefore, to improve reduced-fat products, several alternatives have been proposed in recent years. These alternatives are usually either a modification of the cheese-making procedure or the introduction of new technologies (Rodriguez, 1998). Theophilou and Wilbey (2007) succeeded in improving the meltability and decreasing the hardness of low- or reduced-fat Halloumi cheese by lowering the $\mathrm{pH}$ during production.

This study reports on the characteristics of Halloumi cheese, a necessary step for optimizing its production and for creating adequate processing changes, especially for the manufacture of high quality reduced- and low-fat Halloumi. Considerable investments have been made in the Middle Eastern dairy sector over the last few years, and product development activities geared toward the production of healthier food products for export markets can be of considerable economical benefit to Lebanese and Middle Eastern food companies, especially at a time when competing in the regional and global market is becoming more demanding and more challenging. The objectives of this work were to characterize the physicochemical and sensory properties of bovine and ovine Halloumi of different fat levels and to provide a baseline sensory profile for the different types of samples.

\section{MATERIALS AND METHODS}

\section{Cheese Production}

Formulations. The cheese samples were produced at the Agricultural Research and Extension Center of the American University of Beirut (Hosh Sneid, Lebanon). Twelve batches of Halloumi cheese were produced over 6 consecutive days. The experimental samples were produced in 2 batches and all the cheeses were produced at 3 fat levels (full-fat, reduced-fat, and lowfat) for 2 types of milk (bovine and ovine). Accordingly, the total number of samples was 12 (2 types $\times 3$ fat levels $\times 2$ batches).

Processing. For each batch, $175 \mathrm{~L}$ of raw milk was batch pasteurized at $70^{\circ} \mathrm{C}$ for $20 \mathrm{~min}$ in a cheese vat. To produce low-fat cheese, the milk was first heated 
to $35^{\circ} \mathrm{C}$ and then skimmed using a cream separator (Warenhandels GmbH, Treibach, Austria). Whole milk and skim milk were then recombined to provide milk with varying fat contents $(0.9$ to $2.5 \%)$ to produce the reduced- and low-fat cheeses, and the mixture obtained was pasteurized at $70^{\circ} \mathrm{C}$ for $20 \mathrm{~min}$. To produce full-fat, reduced-fat, and low-fat cheeses from bovine milk, milk fat was standardized at $4,1.7$, and $0.9 \%$, respectively. The 2 batches of cheese obtained had fat contents of $20.88 \%(\mathrm{SD}=0.31)$ and $19.94 \%(\mathrm{SD}=0.54)$ for full-fat cheese, $12.99 \%(\mathrm{SD}=0.77)$ and $13.38 \%(\mathrm{SD}=0.56)$ for reduced-fat, and $6.02 \%(\mathrm{SD}=0.78)$ and $4.81 \%(\mathrm{SD}$ $=0.39$ ) for low-fat, respectively. To produce full-fat, reduced-fat, and low-fat ovine cheese, milk fat was standardized at 6 and $6.6 \%$ for the 2 batches of fullfat, $2.5 \%$ for reduced-fat, and $1.7 \%$ for low-fat cheese. The 2 batches of cheese obtained had fat contents of $23.10 \%(\mathrm{SD}=0.61)$ and $21.01 \%(\mathrm{SD}=0.47)$ for full-fat cheese, $12.99 \%(\mathrm{SD}=1.12)$ and $11.96 \%(\mathrm{SD}=0.39)$ for reduced-fat, and $6.83 \%(\mathrm{SD}=0.61)$ and $7.61 \%$ (SD $=0.71$ ) for low-fat cheese, respectively. The milk fat levels for the 2 types of milks were selected based on preliminary trials to produce Halloumi samples that conformed to the Cypriot standards for full-fat (25.75 $\pm 3.14 \%$ ), reduced-fat (at least $25 \%$ fat reduction from full-fat), and low-fat (at least 50\% fat reduction from full-fat) Halloumi cheese (Papademas et al., 2000). In addition, the protein and casein contents of the milks were tested in preliminary tests a few days before the experiment and, accordingly, the milk fat levels were adjusted to produce consistent casein:fat ratios $( \pm 0.2)$ in the milk for a specific fat level for both types of milk (Haddadin et al., 1995).

After pasteurization, milk was cooled to $37 \pm 1^{\circ} \mathrm{C}$ and $\mathrm{CaCl}_{2}$ was added at $0.15 \%$. After stirring, rennet (Chy-Max, Chr. Hansen, Hørsholm, Denmark) was added at $0.04 \%$ and the milk was stirred again for 2 min. The curd was left to form for $35 \mathrm{~min}$, and then the coagulum was cut into pieces in the form of a $1-\mathrm{cm}^{3}$ dice. The curd was left to rest for $5 \mathrm{~min}$, and then it was transferred to square metallic molds lined with cheesecloth. The cloth was folded to cover the upper surface of the curd. The curd was then pressed for 60 min. A pressure of $300 \mathrm{kPa}$ was applied for the first 15 min then the pressure was increased to $400 \mathrm{kPa}$ for the remaining time. In the meantime, the whey was heated to around $95^{\circ} \mathrm{C}$ to allow the whey proteins to aggregate. Citric acid was added at $0.6 \%$ to facilitate the coagulation and floating of the whey protein. The protein aggregates were removed using a perforated metallic scoop. The pressed curd was cut into approximately $10-\times 15-\mathrm{cm}$ rectangular pieces and placed in the hot whey. The blocks were cooked in the whey for 20 to $40 \mathrm{~min}$ and were removed once they had floated to the surface. The cooked blocks were allowed to cool before being folded. The folded cheese blocks were then placed in plastic containers where pasteurized brine $(9 \%)$ was added and the containers were transferred to a walk-in cooler $\left(4^{\circ} \mathrm{C}\right)$.

Storage. The 12 batches of cheese were stored in plastic containers filled with pasteurized brine (9\%) before sensory evaluation. The cheese stored in brine was also used for the physicochemical analyses and texture measurements. In addition, representative samples were selected from the different batches, ground using a Moulinex food grinder (Food Chopper, Moulinex, Ecully, France) and either analyzed (moisture, ash, calcium, and sodium) or placed in glass jars before being stored in the freezer $\left(-20^{\circ} \mathrm{C}\right)$.

\section{Chemical Analyses}

Representative samples were prepared according to (AOAC, 2000; method 920.11). The methods of AOAC (2000) were used to determine moisture content (method 948.12), ash content (method 935.42), calcium and sodium contents of the cheese (method 991.25), fat content of the cheese (method 933.05), and protein content (method 920.125). The percentage of protein was calculated using a conversion factor of 6.38. The fat content of the milk was determined according to the Gerber method (IDF, 1991). All determinations were carried out in triplicate.

\section{Instrumental Texture Analysis}

The evaluation of the cheeses' textural properties was carried out using 3 samples from each batch. Therefore, a total of 36 samples were tested ( 3 replicates $\times 2$ types of milk $\times 3$ fat levels $\times 2$ batches). A texture analyzer (QTS25, Brookfield Engineering Labs, Middleboro, MA) equipped with a $38.1-\mathrm{mm}$ cylindrical probe was used. The speed of the cross-head was $60 \mathrm{~mm} / \mathrm{min}$ and the time elapsed between the first and second bite was $8 \mathrm{~s}$ after compressing the sample by $25 \%$ of its height $(0.5 \mathrm{~cm})$. Sample cubes $\left(2 \mathrm{~cm}^{3}\right)$ were taken from the center of the cheese blocks. After being cut, the samples were allowed to temper for $20 \mathrm{~min}$ and reach room temperature before testing. Texture profile analysis was performed on the samples with adhesiveness, chewiness, cohesiveness, hardness, and springiness being the tested parameters.

\section{Descriptive Analysis}

The panel consisted of 11 members. The panelists were 8 females and 3 males (mean age $=25$, range $=$ $22-34$, SD $=3.59$ ) who were selected based on their 
Table 1. Terms used in descriptive analysis of ovine and bovine Halloumi cheese

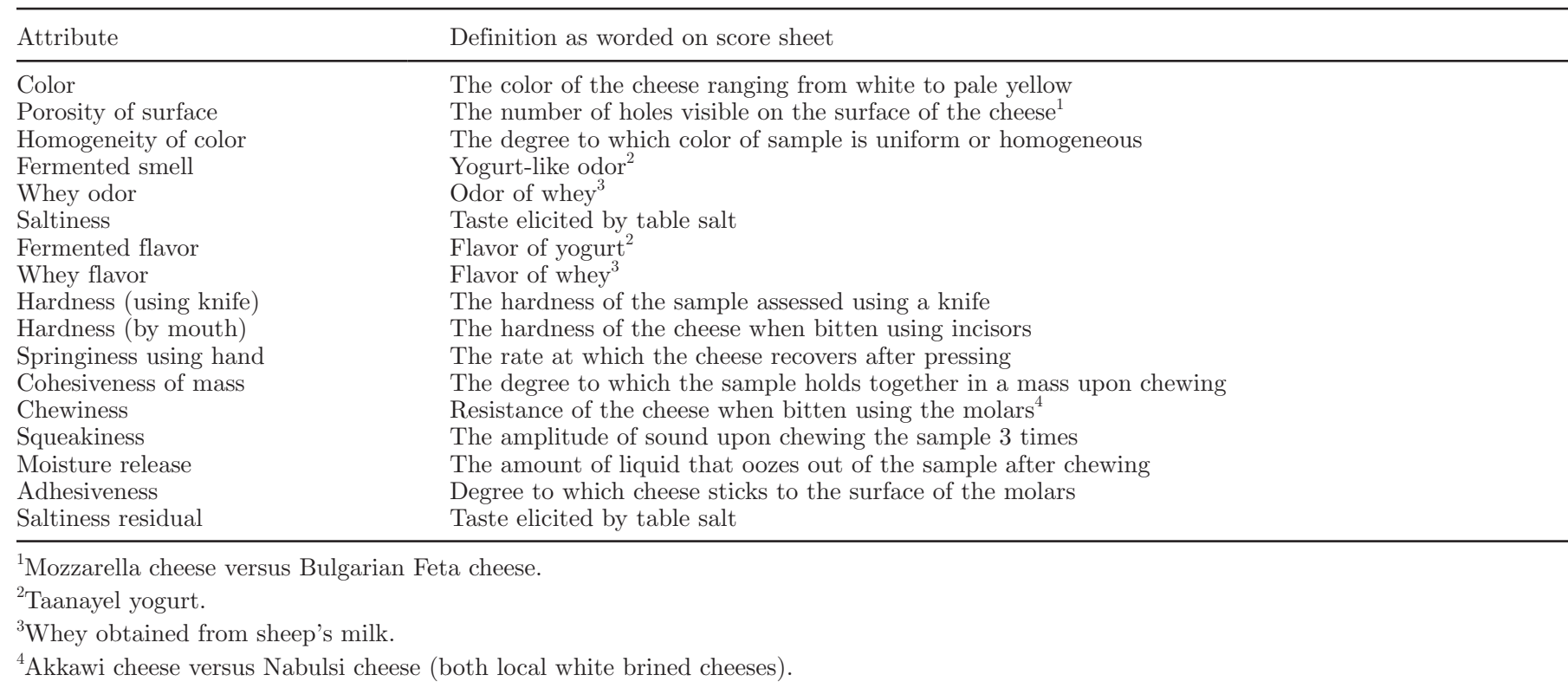

willingness to participate and time availability. The panelists were mainly graduate students in the Nutrition and Food Science Department at the American University of Beirut. They were not informed about the true nature of the project or that of the cheese; however, they were all familiar with Halloumi cheese and its characteristics. The study was approved by the Institutional Review Board of the American University of Beirut.

The panelists were trained over six 1-h sessions. During the training sessions, the panelists were provided with different commercial and experimental samples. They were asked to examine the samples and describe the appearance, aroma, flavor, texture, and residual taste of the cheeses. Once the panelists had tasted the different samples, they were asked to provide a list of attributes individually covering appearance, aroma, flavor, texture, and residual. A round-table discussion was then conducted to reach an agreement among the panelists. The panelists were also asked to define the attributes. Reference standards were chosen for some attributes and were used to anchor the descriptors. Panelists' performance was assessed during the training sessions by conducting analyses of variance on their training ratings to check for replicate effect and 2-way interactions (panelist $\times$ sample, panelist $\times$ replicate, and sample $\times$ replicate). In addition, ranking tests were performed and the performance of the panelists was communicated to them during the training sessions. The final list of 17 attributes with definitions, anchor words, and standards is presented in Table 1.
The panelists attended 6 evaluation sessions conducted over a period of $3 \mathrm{~d}$. On each test day, the panelists performed 2 tastings (one morning and one afternoon tasting) at least $1 \mathrm{~h}$ after their last meal. The sessions were conducted in the sensory evaluation laboratory in the Nutrition and Food Science department at the American University of Beirut. Panelists were seated in individual booths with white fluorescent lighting and were provided with a tray, samples, water, knife, napkins, and the sensory ballot. Four different samples were served at each session and the panelists were instructed to wait for 2 min between samples and to rinse their mouths with water. The cheese samples were cut into $4.5 \times 2 \times 1.5 \mathrm{~cm}$ rectangular slices and $1.5-\mathrm{cm}^{3}$ cubes. Each panelist was given 1 slice and 2 cubes of each sample and the samples were presented in 150-mL covered plastic cups coded with 3-digit random numbers. The samples were prepared $1 \mathrm{~d}$ before serving and were stored in the refrigerator $\left(4^{\circ} \mathrm{C}\right)$ until serving. The order of presentation of the samples was counterbalanced based on the design for 12 samples as suggested by Macfie and Bratchell (1989). The samples were assessed in duplicate evaluations (3 sessions/replicate) with all 12 samples (2 types of milk $\times 3$ fat levels $\times 2$ batches) served within each replicate.

The sensory evaluation was performed by rating the intensity of the attributes generated during the training sessions on a 15-cm line scale (Guinard and Cliff, 1987; Guinard et al., 1999). Panelists were compensated with a small monetary sum as compensation for their participation. 


\section{Hedonic Evaluation}

Eighty-four panelists participated in the acceptability test $($ mean age $=24.3$, range $=18-57, \mathrm{SD}=8.1)$. The panelists were mainly students, staff, and faculty members at the American University of Beirut. They were selected based on their willingness to participate and time availability. The participants were given a small monetary sum at the end of the study as compensation for their participation.

The panelists assessed the 12 samples in 2 sessions over 2 consecutive days in a similar setting to the one described above. Six different samples were served at each session and the panelists were instructed to rinse their mouths with water between samples. The cheese samples were cut into $1.5-\mathrm{cm}^{3}$ cubes and each panelist was provided 2 cheese cubes. The samples were presented in 150-mL covered plastic cups coded with 3-digit random numbers. The samples were prepared $1 \mathrm{~d}$ before serving and were stored in the refrigerator $\left(4^{\circ} \mathrm{C}\right)$ until $15 \mathrm{~min}$ before sensory evaluation. The order of presentation of the samples was counterbalanced based on the design for 6 samples as suggested by Macfie and Bratchell (1989).

At the beginning of each session, the panelists were asked to rate their mood on a 7 point labeled categories smiley scale (Chen et al., 1996; Morien et al., 2008) and their hunger on a $15-\mathrm{cm}$ line scale. The panelists were then asked to taste the samples in the order provided and to rate the samples for overall acceptability and for the acceptability of texture on a 9-point hedonic scale $(1=$ dislike extremely to $9=$ like extremely; Peryam and Pilgrim, 1957). The questionnaire also included a food action rating scale (FACT; Schutz, 1964). The FACT scale consists of 9 categories assigned to statements listed from the most positive attitude (category 1, "I would eat this every opportunity I have") to the most negative food attitude (category 9, "I would eat this only if I were forced to").

\section{Statistical Analyses}

Analysis of variance using the Mixed procedure of SAS (version 8.02, SAS Institute Inc., Cary, NC) was performed to assess panelist performance (ability to discriminate among the samples, reproducibility, and concept alignment) during panel training, and to assess the significance of the chemical, physical, and sensory differences among the experimental samples in the evaluation sessions. In the statistical model for the descriptive sensory data, the response variable was the sensory attribute of the samples. The factors in the model were milk type (ovine or bovine), fat level (fullfat, reduced-fat, or low-fat), panelist, batch (nested within milk type and fat level), replicate (nested within batch), and their 2-way interactions. Panelist and batch were included as random effects and milk type, fat level, and replicate were fixed effects in the model. Each of the main effects was tested as well as their interactions. Panelist was not included in the chemical or physical analyses models. In addition, the sensory acceptability model included mood and hunger as covariates and did not include replicate. Significant means for the sensory analyses were separated by Tukey's honestly significant difference test. Significance was established at $\alpha$ $<0.05$. Moreover, principal components analysis was performed to extract the main factors that summarize several sensory attributes, using the 24 means ( 2 types of milk $\times 3$ fat levels $\times 2$ batches $\times 2$ replicates) obtained from descriptive analysis. These analyses were also performed using the SAS statistical software.

\section{RESULTS AND DISCUSSION}

\section{Physical and Chemical Analyses}

Results of the chemical analyses are summarized in Table 2. Type of milk had a significant $(P<0.01)$ effect on the moisture and protein levels of the Halloumi cheese samples, whereas fat level had a significant effect on moisture, fat, protein $(P<0.001)$, and ash $(P<$ $0.05)$ levels. No significant differences were obtained from type of milk for ash, $\mathrm{pH}$, fat, sodium, and calcium, whereas fat level did not have a significant effect on $\mathrm{pH}$, sodium, or calcium. Moreover, no significant type of milk $\times$ fat level interaction was obtained for any of the chemical analyses.

Samples made with bovine milk had higher moisture levels and lower protein contents than samples of ovine origin. Milci et al. (2005) reported similar differences between ovine and bovine cheeses. Unlike results obtained in previous studies (Papademas and Robinson, 2000; Milci et al., 2005), the $\mathrm{pH}$ and the fat levels did not differ significantly between ovine and bovine samples. The absence of significant differences in the fat levels was probably caused by low fat recovery during cheese making of the ovine samples.

Low-fat cheese had the highest moisture level whereas full-fat cheese had the lowest level. The ash level was significantly lower $(P<0.05)$ in full-fat cheese compared with low-fat cheese, probably caused by the moisture and differences. The fat levels for the different samples were consistent with the experimental plan, as shown by the means for fat levels (Table 2). The fat levels for the samples in this work were also consistent with the Cypriot standards for full-fat, reduced-fat (25\% fat reduction compared with full-fat), and low-fat (50\% fat reduction) cheeses. 
Table 2. Significance of the effects ( $F$-values) of type of milk, fat level, and their interactions on the chemical properties and least squares means of the chemical properties of Halloumi samples

\begin{tabular}{|c|c|c|c|c|c|c|c|c|}
\hline Chemical analyses & \multicolumn{3}{|c|}{ Effects } & \multicolumn{2}{|c|}{ Type of milk } & \multicolumn{3}{|c|}{ Fat level } \\
\hline Fat $(\%)$ & 3.51 & $314.66^{* * *}$ & 2.80 & 13.01 & 13.92 & $21.23^{\mathrm{a}}$ & $12.83^{\mathrm{b}}$ & $6.32^{\mathrm{c}}$ \\
\hline Protein (\%) & $27.40^{* *}$ & $30.98^{* * *}$ & 1.17 & $20.99^{\mathrm{a}}$ & $26.02^{\mathrm{b}}$ & $18.28^{\mathrm{a}}$ & $25.15^{\mathrm{b}}$ & $27.09^{\mathrm{b}}$ \\
\hline Ash $(\%)$ & 0.48 & $8.76^{*}$ & 1.44 & 6.08 & 6.21 & $5.63^{\mathrm{a}}$ & $6.26^{\mathrm{ab}}$ & $6.55^{\mathrm{b}}$ \\
\hline Calcium (mg/100 g) & 0.06 & 0.77 & 0.48 & 695.83 & 680.00 & 639.17 & 737.50 & 687.08 \\
\hline
\end{tabular}

${ }^{\mathrm{a}-\mathrm{c}}$ Means within a type of milk or fat level and within a row with different superscripts are significantly different $(P<0.05)$.

${ }^{1} \mathrm{~T}=$ type of milk; FL $=$ fat level.

${ }^{*} P<0.05 ;{ }^{* *} P<0.01 ;{ }^{* * *} P<0.001$.

The results of the texture analyses are summarized in Table 3. Analyses of variance revealed that the type of milk significantly $(P<0.01)$ affected the adhesiveness, chewiness, and hardness of the cheese, whereas fat levels significantly affected chewiness, hardness $(P$ $<0.01)$, adhesiveness, and cohesiveness $(P<0.05)$. No significant effects were obtained for type of milk on cohesiveness or springiness and the same applied for fat level on springiness. A significant type of milk $\times$ fat level interaction was obtained only for chewiness but not for the other variables.

Samples produced from ovine milk were significantly chewier, gummier, harder, and less adhesive than samples produced from bovine milk. The results of this work for hardness were in agreement with previous work in which it was reported that cheeses produced from sheep's milk were harder than cheeses produced from cow's milk, although the differences were not statistically significant (Pappa et al., 2007). Similar textural differences between ovine and bovine cheeses have been reported by Ponce de Leon-Gonzalez et al. (2002) in Muenster-type cheese. The bovine/ovine milk cheeses, assessed using texture profile analysis, were significantly harder and chewier than the bovine milk cheeses throughout the aging period (Ponce de LeonGonzalez et al., 2002).

Reduced-fat and low-fat cheeses were significantly chewier and harder than full-fat cheese. However, lowfat and reduced-fat cheeses did not differ significantly in the previously mentioned parameters. Papademas et al. (2000) and Theophilou and Wilbey (2007) measured some physical properties of full-fat, low-fat, and reduced-fat Halloumi using a texture profile analyzer and reported a similar increase in chewiness and hardness with a lower fat content. Papademas et al. (2000) noted that differences in chewiness and hardness between fullfat and less-fat or reduced-fat varieties is a reflection of the higher protein content rather than changes in moisture or fat. As for the significant type of milk $\times$ fat level interaction for chewiness, the cheeses had the following means for chewiness: $7,507.73 \mathrm{~g} \cdot \mathrm{mm}$ for reducedfat ovine, $6,110.09 \mathrm{~g} \cdot \mathrm{mm}$ for low-fat ovine, 4,271.79 $\mathrm{g} \cdot \mathrm{mm}$ for low-fat bovine, $4,009.20 \mathrm{~g} \cdot \mathrm{mm}$ for reduced-fat bovine, $2,111.08 \mathrm{~g} \cdot \mathrm{mm}$ for full-fat ovine, and 1,958.29 $\mathrm{g} \cdot \mathrm{mm}$ for full-fat bovine. It is clear from these means that ovine samples were chewier than bovine samples

Table 3. Significance of the effects ( $F$-values) of type of milk, fat level, and their interactions on the physical properties and least squares means of the physical properties of Halloumi samples

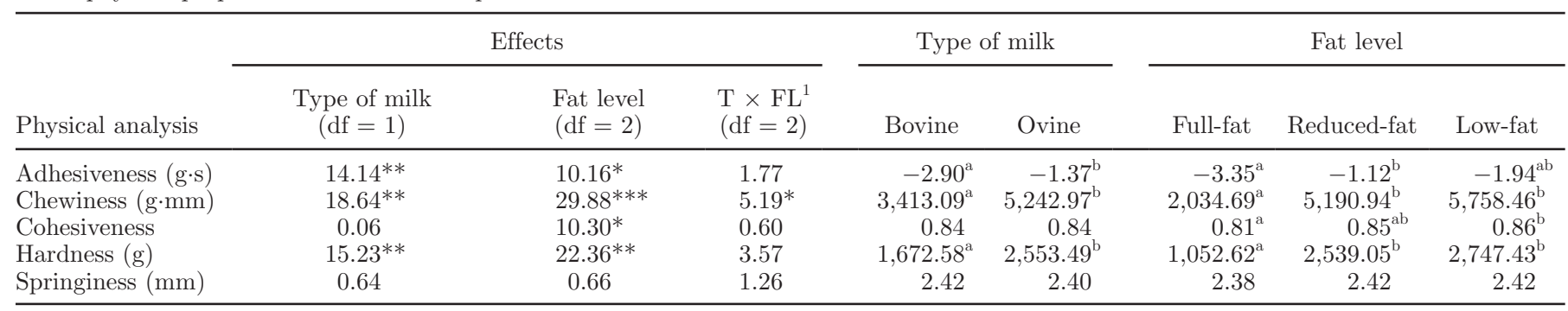

${ }^{\mathrm{a}, \mathrm{b}}$ Means within a type of milk or fat level and within a row with different superscripts are significantly different $(P<0.05)$.

${ }^{1} \mathrm{~T}=$ type of milk; FL $=$ fat level.

${ }^{*} P<0.05 ;{ }^{* *} P<0.01 ;{ }^{* * *} P<0.001$ 
for the same fat level, although this trend was only significant for the reduced-fat level. In addition, reducedfat cheese was less adhesive than full-fat cheese, but reduced-fat cheese was not significantly different from the 2 other types of cheese for adhesiveness. A decrease in the adhesiveness of Cheddar cheese with a reduction in its fat content was also reported by Bryant et al. (1995). Low-fat cheese was more cohesive than full-fat cheese but reduced-fat cheese was not significantly different from the 2 other types of cheese for cohesiveness. The lack of differences on springiness has been reported in previous work (Papademas et al., 2000)

\section{Descriptive Analysis}

ANOVA and Tukey's Test. The results of the analyses of variance for the sensory data and the least squares means of all 17 sensory attributes for each of the 3 fat levels (full-fat, low-fat, and reduced-fat) and for both types of milks (ovine and bovine) are summarized in Table 4. Analyses of variance revealed significant differences between the ovine and bovine cheeses on color, hardness using knife, hardness by mouth, and squeakiness $(P<0.05)$. Differences were also obtained on fat level for color, hardness by mouth, moisture release $(P$ $<0.05)$, and hardness using knife $(P<0.01)$.

Ovine cheese was found to be more yellow than bovine cheese, whereas bovine cheese was found to be more squeaky. The results for color were consistent with previous studies that also showed that cheese from bovine origin is whiter (Papademas and Robinson, 2001), but contradicted other studies which reported that ovine cheese was whiter than bovine (Robinson 1991; Papademas and Robinson, 1998). In addition, ovine cheese was harder than bovine cheese (by knife and by mouth) and Ozer et al. (2002) reported similar results for hardness of Urfa cheese. Papademas and Robinson (2000) found that ovine cheese was significantly more springy and chewy than bovine cheese. However, the number of the panelists involved in their work was small (11 panelists) and the extent of their training was limited; therefore, the results of their study could be considered exploratory in nature.

Full-fat cheese was significantly $(P<0.05)$ whiter, less hard (by knife and by mouth), and more moist than the reduced-fat and low-fat cheeses. Low-fat cheese had higher mean ratings for yellow, hardness using knife, and hardness by mouth, and lower ratings for moisture release than reduced-fat cheese, although these differences were not statistically significant.

Previous studies (Papademas et al., 2000) showed similar trends for color, moisture release, and hardness in full-fat, low-fat, and reduced-fat cheeses. Hardness in low-fat cheeses correlates most closely with protein content but not with fat content (Olson and Johnson, 1990). Full-fat cheese was also found to be more moist than the reduced-fat and low-fat cheeses although moisture content increased as the fat content decreased (Table 2). In fact, cheeses with reduced fat levels are usually described as excessively dry and possibly grainy, because of the greater structural matrix per unit crosssectional area. (Rodriguez, 1998). The trained panel failed to identify statistically significant differences in flavor between the different samples. Similar results have been reported by Papademas and Robinson (2000) and Milci et al. (2005). Significant differences have been reported in matured cheese as flavor notes tend to increase in intensity at maturity (Papademas and Robinson, 2000). Although the texture differences on hardness were consistent between the instrumental and sensory descriptive measurements, in addition to similar trends for differences between fat levels on cohesiveness and chewiness (though not significantly different for sensory measurements), it is interesting to note that the instrumental assessment of texture revealed more subtle differences than the subjective panelists' assessment. Texture profile analysis showed significant differences between the different types of cheeses on all of the tested parameters except springiness, whereas panelists' sensory assessments revealed differences on hardness and squeakiness only. Romeih et al. (2002) reported similar differences between the instrumental texture assessment and panelists' evaluation. Their instrumental assessment of texture revealed significant differences on hardness, cohesiveness, springiness, and chewiness between full-fat and low-fat cheeses, whereas panelists' evaluation showed slightly different scores on hardness and crumbliness although these differences were not statistically significant.

There were no significant fat $\times$ type of milk interactions. There were no major inconsistencies in the panelists' ratings, as shown by the absence of replicate effect, with the exception of porosity of surface $(P<0.01)$ and saltiness $(P<0.05)$. The fat $\times$ replicate interaction was significant for porosity of surface $(P<0.001)$, hardness by mouth $(P<0.01)$, and cohesiveness of mass $(P<$ $0.05)$, whereas a type of milk $\times$ replicate interaction was obtained for porosity of surface $(P<0.05)$ and whey odor $(P<0.05)$.

Principal Component Analysis. Figure 1 illustrates the principal components (PC) analysis for the first $2 \mathrm{PC}$ (denoted PC1 and PC2), which accounted for $58.2 \%$ ( $45.1 \%$ for $\mathrm{PC} 1$ and $13.1 \%$ for $\mathrm{PC} 2$ ) of the variation in the sensory attributes' scores. There are 4 clusters of attributes in the first $2 \mathrm{PC}$.

The first PC (displayed horizontally on Figure 1) separated attributes based on fat content. The positive side of PC1 included higher values on attributes typi- 
Table 4. Significance of effects of type of milk, fat level, replicate, and their interactions on the sensory properties of Halloumi samples and least squares means of descriptive analysis attributes (rated on a 15 -cm line scale)

\begin{tabular}{|c|c|c|c|c|c|c|c|c|c|c|c|}
\hline \multirow[b]{2}{*}{ Attributes } & \multicolumn{6}{|c|}{ Effect $^{1}$} & \multicolumn{2}{|c|}{ Type of milk } & \multicolumn{3}{|c|}{ Fat level $^{2}$} \\
\hline & $\mathrm{T}(\mathrm{df}=1)$ & $\mathrm{FL}(\mathrm{df}=2)$ & $\mathrm{R}(\mathrm{df}=3)$ & $\mathrm{FL} \times \mathrm{T}(\mathrm{df}=2)$ & $\mathrm{FL} \times \mathrm{R}(\mathrm{df}=6)$ & $\mathrm{T} \times \mathrm{R}(\mathrm{df}=3)$ & Bovine & Ovine & $\mathrm{FF}$ & $\mathrm{RF}$ & $\mathrm{LF}$ \\
\hline Color & $45.42^{*}$ & $54.99 *$ & 1.72 & 11.87 & 0.48 & 0.17 & $4.93^{\mathrm{a}}$ & $8.94^{\mathrm{b}}$ & $3.45^{\mathrm{a}}$ & $8.33^{\mathrm{b}}$ & $9.02^{\mathrm{b}}$ \\
\hline Porosity of surface & 2.72 & 1.86 & $5.42^{* *}$ & 12.20 & $4.42^{* * *}$ & $3.09 *$ & 7.95 & 8.56 & 7.97 & 8.74 & 8.06 \\
\hline Homogeneity of color & 10.27 & 17.90 & 2.22 & 1.37 & 1.08 & 0.28 & 10.23 & 7.43 & 12.30 & 7.47 & 6.72 \\
\hline Fermented odor & 0.59 & 1.35 & 0.18 & 0.28 & 1.48 & 0.60 & 6.07 & 5.78 & 5.91 & 6.28 & 5.58 \\
\hline Whey odor & 4.50 & 0.41 & 0.68 & 0.23 & 1.63 & $3.08^{*}$ & 8.50 & 9.43 & 8.98 & 8.76 & 9.15 \\
\hline Saltiness & 0.51 & 0.00 & $3.18^{*}$ & 0.99 & 1.24 & 0.71 & 8.68 & 9.04 & 8.87 & 8.87 & 8.84 \\
\hline Fermented flavor & 0.93 & 1.58 & 2.34 & 0.98 & 0.73 & 0.62 & 5.41 & 5.80 & 5.97 & 5.70 & 5.15 \\
\hline Whey flavor & 4.31 & 0.01 & 2.56 & 1.00 & 0.56 & 0.17 & 7.25 & 8.40 & 7.88 & 7.80 & 7.80 \\
\hline Hardness using knife & $32.48^{*}$ & $151.84^{* *}$ & 1.25 & 7.98 & 2.22 & 0.40 & $7.86^{\mathrm{a}}$ & $9.40^{\mathrm{b}}$ & $4.83^{\mathrm{a}}$ & $9.65^{\mathrm{b}}$ & $11.40^{\mathrm{b}}$ \\
\hline Springiness using hand & 1.18 & 1.41 & 0.23 & 2.53 & 1.11 & 0.29 & 8.49 & 7.60 & 8.95 & 7.90 & 7.29 \\
\hline Hardness by mouth & $32.69^{*}$ & $84.63^{*}$ & 0.95 & 10.16 & $3.45^{* *}$ & 0.82 & $7.30^{\mathrm{a}}$ & $8.62^{\mathrm{b}}$ & $4.13^{\mathrm{a}}$ & $8.49^{\mathrm{b}}$ & $11.27^{\mathrm{b}}$ \\
\hline Cohesiveness of mass & 0.14 & 2.69 & 0.24 & 0.61 & $2.28^{*}$ & 0.34 & 7.50 & 7.66 & 6.38 & 7.81 & 8.55 \\
\hline Chewiness & 0.42 & 4.39 & 0.27 & 0.36 & 1.51 & 0.24 & 7.24 & 7.59 & 5.87 & 7.45 & 8.93 \\
\hline Squeakiness & $41.91^{*}$ & 4.06 & 1.67 & 11.31 & 0.89 & 0.79 & $7.64^{\mathrm{a}}$ & $5.78^{\mathrm{b}}$ & 7.78 & 6.66 & 5.69 \\
\hline Moisture release & 13.59 & $51.18^{*}$ & 0.07 & 7.65 & 0.92 & 1.79 & 8.51 & 7.14 & $10.15^{\mathrm{a}}$ & $7.56^{\mathrm{b}}$ & $5.77^{\mathrm{b}}$ \\
\hline Adhesiveness & 9.58 & 0.60 & 0.97 & 0.91 & 0.76 & 1.14 & 7.33 & 8.29 & 7.61 & 8.06 & 7.77 \\
\hline Saltiness residual & 0.27 & 0.46 & 1.16 & 0.67 & 0.65 & 0.18 & 8.40 & 8.11 & 8.66 & 8.16 & 7.95 \\
\hline
\end{tabular}

${ }^{\mathrm{a}, \mathrm{b}}$ Means within a type of milk or fat level and within a row with different superscripts are significantly different $(P<0.05)$.

${ }^{1} \mathrm{~T}=$ type of milk; $\mathrm{FL}=$ fat level; $\mathrm{R}=$ replicate.

${ }^{2} \mathrm{FF}=$ full-fat; $\mathrm{RF}=$ reduced-fat; $\mathrm{LF}=$ low-fat

${ }^{*} P<0.05 ;{ }^{* *} P<0.01 ;{ }^{* * *} P<0.001$. 
PCA for Halloumi Samples

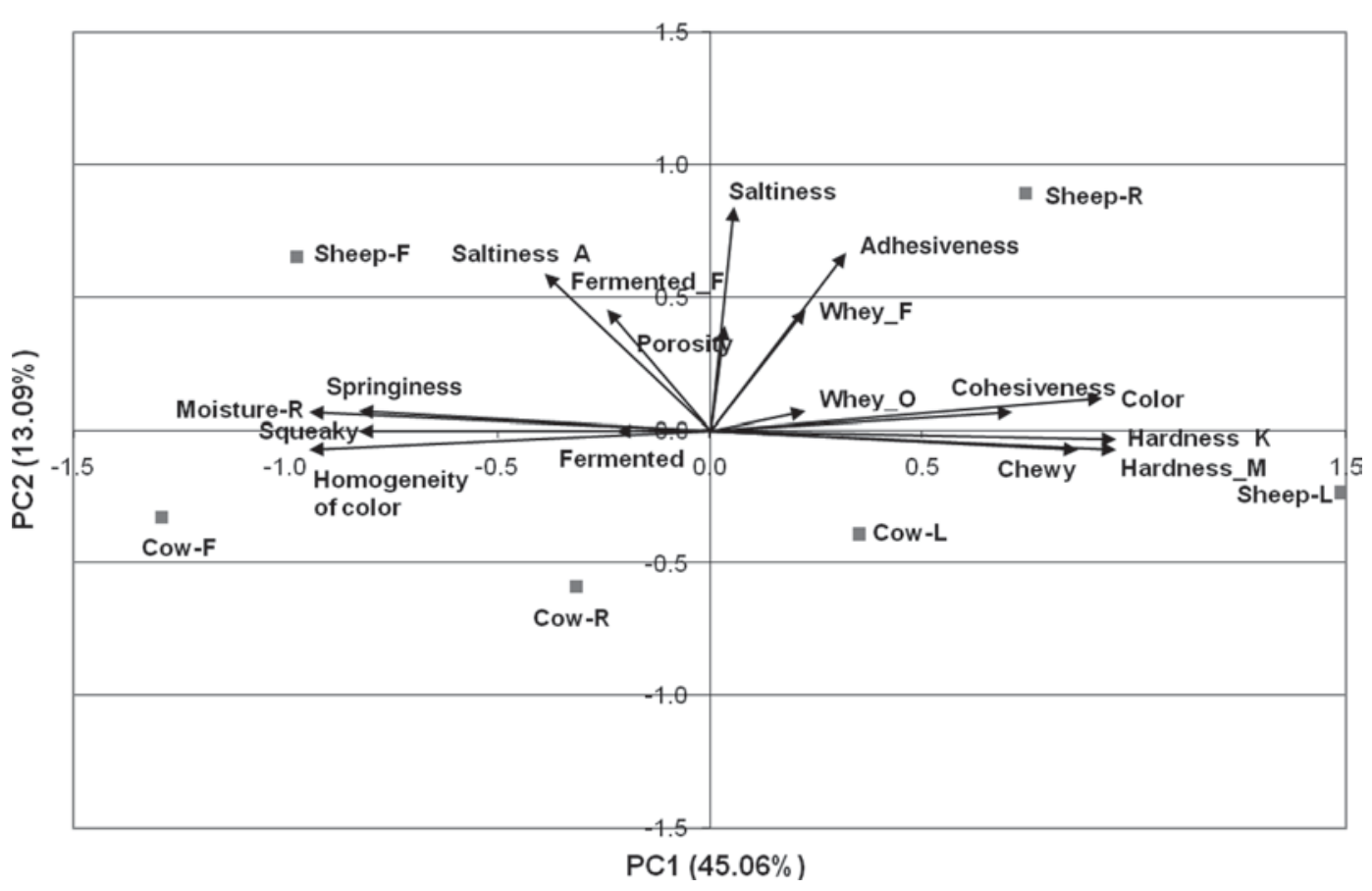

Figure 1. Principal components plot of Halloumi samples and attributes. Cow-F = full-fat bovine cheese; Sheep- $\mathrm{F}=\mathrm{full}-\mathrm{fat}$ ovine cheese; Cow- $\mathrm{R}=$ reduced-fat bovine cheese; Sheep- $\mathrm{R}=$ reduced-fat ovine cheese; Cow- $\mathrm{L}=$ low-fat bovine cheese; Sheep- $\mathrm{L}=$ low-fat ovine cheese.

cally found in reduced-fat and low-fat varieties. Lowfat bovine cheese, reduced-fat ovine cheese, and low-fat ovine cheese are all part of this cluster. On the other hand, the negative side of PC1 included the full-fat ovine and bovine cheeses, in addition to reduced-fat bovine. Although the reduced-fat bovine sample belonged to this group, it lays on the border of the opposite cluster. The ratings given by the panelists to the reduced-fat bovine cheese were intermediate between the full-fat varieties and the remaining low-fat and reduced-fat varieties (data not shown), which explains its location on the graph.

As for $\mathrm{PC} 2$, it separated attributes based on type of milk. The positive side of PC2 (third cluster, upper quadrants) was characterized by attributes that described ovine cheese. Full-fat and reduced-fat ovine cheeses belonged to this cluster. Full-fat, reduced-fat, and low-fat bovine cheese as well as low-fat ovine cheese belonged to the negative side of PC2 (fourth cluster, lower quadrants). The fourth cluster was the opposite of the third cluster, mostly characterized by the absence of the previously mentioned attributes.

\section{Hedonic Evaluation}

The least squares means of the acceptability tests are summarized in Table 5. Type of milk had a signifi- cant effect $(P<0.01)$ on overall acceptability, texture acceptability, and FACT. Analysis of variance also revealed that overall acceptability, FACT $(P<0.01)$, and texture acceptability $(P<0.001)$ were affected by fat level. There was no significant fat $\times$ type of milk interaction.

Halloumi produced from bovine milk received higher scores on overall acceptability and texture acceptability, which explained the fact that ovine cheese scored significantly higher on FACT. Previous work (Papademas and Robinson, 2001) showed that the overall preference for one type of cheese rather than another seems to be influenced by the age of the panelists because young panelists (average age $23 \pm 2 \mathrm{SD}$ ) showed a strong overall preference for cheeses produced from caprine/ovine origin, whereas older panelists (average age $45 \pm 5 \mathrm{SD}$ ) did not express any preference. Our findings suggested that panelists showed a higher acceptability for bovine cheese, probably because they were not familiar with the distinctive flavor and aroma of cheese produced from sheep's milk, especially given that all commercial Halloumi cheeses that are marketed in the urban areas are made from bovine milk because of market availability. This phenomenon stresses the importance of taste education and its effect on food preferences. Traditional Halloumi cheese produced from a goat/sheep milk mixture contained a greater number of indigenous 
Table 5. Least squares means of the acceptability scores (rated on a 9-point category hedonic scale) of Halloumi samples for the 2 milk types and the 3 fat levels

\begin{tabular}{|c|c|c|c|c|c|}
\hline \multirow[b]{2}{*}{ Acceptability } & \multicolumn{2}{|c|}{ Type of milk } & \multicolumn{3}{|c|}{ Fat level } \\
\hline & Bovine & Ovine & Full-fat & Reduced-fat & Low-fat \\
\hline Overall acceptability & $5.60^{\mathrm{a}}$ & $4.26^{\mathrm{b}}$ & $6.06^{\mathrm{a}}$ & $4.82^{\mathrm{b}}$ & $3.90^{\mathrm{b}}$ \\
\hline Texture acceptability & $5.62^{\mathrm{a}}$ & $4.01^{\mathrm{b}}$ & $6.35^{\mathrm{a}}$ & $4.68^{\mathrm{b}}$ & $3.42^{\mathrm{c}}$ \\
\hline $\mathrm{FACT}^{1}$ & $5.09^{\mathrm{a}}$ & $6.27^{\mathrm{b}}$ & $4.60^{\mathrm{a}}$ & $5.80^{\mathrm{b}}$ & $6.65^{\mathrm{b}}$ \\
\hline
\end{tabular}

${ }^{\mathrm{a}-\mathrm{c}}$ Means within a type of milk or fat level and within a row with different superscripts are significantly different $(P<0.05)$.

${ }^{1} \mathrm{FACT}$ is the food action rating scale used.

flavor compounds than the industrially produced bovine Halloumi cheese (Papademas, 2006). Overall acceptability scores given by the panelists (Table 5) seem to be in agreement with the results obtained by Milci et al. (2005) and in contradiction with the results obtained by Papademas and Robinson (2001). In the study conducted by Milci et al. (2005), the panelists were asked to rate the samples on a 20-point scale. The Halloumi cheese made from bovine milk received higher scores $(13.17 \pm 1.69)$ than the cheeses made from ovine milks $(12.25 \pm 1.27)$, although the differences were not statistically significant. On the other hand, in the study conducted by Papademas and Robinson (2001), the hedonic mean scores (\%) given by the older panelists (average age $45 \pm 5 \mathrm{SD}$ ) to the samples produced from ovine milk were 35.9 and 42.1 and those given to bovine cheese were 35.2. The young panelists (average age 23 $\pm 2 \mathrm{SD}$ ) gave ovine cheeses mean scores of 78.4 and 61.1 and bovine cheeses mean scores of 52.4 .

Full-fat cheese received significantly higher scores than the reduced-fat and low-fat varieties on overall acceptability and texture acceptability and lower scores on FACT. There were no significant differences between the low-fat and reduced-fat samples except for texture acceptability. Overall acceptability and texture acceptability decreased with fat level. It is well established that levels of fat in cheese have a direct effect on acceptability (Aziznia et al., 2008; Koca and Metin, 2004). However, results obtained by Papademas et al. (2000) showed that occasional consumers of Halloumi cheese did not show discrimination against the low-fat and reduced-fat varieties and low-fat versions were accepted without complaints. In their study, tasters from England, who were not regular consumers of Halloumi cheese, gave full-fat, less-fat, and reduced-fat Halloumi hedonic sensory scores (\%) of 46, 42, and 47, respectively.

Surprisingly, although the trained panelists did not perceive significant textural differences between the low-fat and reduced-fat samples, acceptability scores indicated that reduced-fat cheese scored significantly higher than low-fat cheese on texture acceptability. It is possible that the combination of hardness and moisture release and their additive effect, in addition to other possible texture parameters, affected the texture acceptability of the cheeses of different fat levels. This phenomenon could also be due to the unlikely possibility of the hedonic evaluation panelists noticing a difference on a textural attribute that was missed by the trained panelists of the descriptive analysis.

\section{CONCLUSIONS}

The results of the study suggested that the chemical and instrumental (and in some cases sensory) textural differences that existed between cheese samples of different fat levels were not always perceived by the consumer. Samples of bovine origin had significantly higher moisture levels and lower protein content than cheeses of ovine origin. In addition, moisture and protein contents increased significantly when fat levels decreased. These chemical differences, in turn, resulted in instrumental textural differences and in some instances sensory textural differences (hardness, squeakiness, and moisture release). Therefore, in terms of instrumental texture results, ovine cheese was significantly chewier, harder, and less adhesive than bovine cheese. Moreover, reduced-fat and low-fat cheeses were significantly chewier and harder than full-fat cheese. However, lowfat and reduced-fat cheeses did not differ significantly in the above mentioned parameters. Reduced-fat cheese was also less adhesive than full-fat cheese, which was not the case for the low-fat versus full-fat cheeses, and low-fat cheese was more cohesive than full-fat cheese.

Sensory evaluation revealed that panelists were sensitive to changes in color and hardness because of significant differences on these attributes but were less perceptive of other textural and flavor changes. Ovine cheese was found to be more yellow and harder than bovine cheese. Full-fat cheese was also found to be significantly whiter and less hard than the reduced-fat and low-fat cheeses. In addition, full-fat cheese was found to be more moist than the other 2 cheese varieties. 
Full-fat cheese received significantly higher scores than the reduced-fat and low-fat varieties on overall acceptability and texture acceptability and lower scores on FACT, and panelists showed higher acceptability to bovine cheese.

Moreover, it is advised to change the conventional Halloumi cheese-making procedure to improve the quality of low-fat varieties and reduce their hardness. Commonly proposed procedures are increasing the moisture content or using protein-based and carbohydrate-based fat replacers.

\section{ACKNOWLEDGMENTS}

The authors thank J. Walker, G. Abi Abdallah, A. Hajj Hassan, J. Eid, W. Boutros, F. Abu Maizar for technical assistance, S. Safar, N. Haddad, and all the panelists for their dedication. The funding by the University Research Board of the American University of Beirut is gratefully acknowledged.

\section{REFERENCES}

AOAC. 2000. Official Methods of Analysis of AOAC International. Vol. II, 17th ed. Association of Official Analytical Chemists, Gaithersburg, MD.

Aziznia, S., A. Khosrowshahi, A. Madadlou, and J. Rahimi. 2008. Whey protein concentrate and gum tragacanth as fat replacers in nonfat yogurt: Chemical, physical, and microstructural properties. J. Dairy Sci. 91:2545-2552.

Bryant, A., Z. Ustunol, and J. Steffe. 1995. Texture of Cheddar cheese as influenced by fat reduction. J. Food Sci. 60:1216-1219, 1236.

Chen, A. W., A. V. A. Resurreccion, and L. P. Paguio. 1996. Age appropriate hedonic scales to measure food preferences of young children. J. Sens. Stud. 11:141-163.

Gibbs, P., and R. Morphitou. 2004. Halloumi: Exporting to retain traditional food products. Br. Food J. 106:569-576.

Guinard, J.-X., and M. Cliff. 1987. Descriptive analysis of Pinot noir wines from Carneros, Napa, and Sonoma. Am. J. Enol. Vitic. 38:211-215.

Guinard, J.-X., D. Yip, E. M. Cubero, and R. Mazzucchelli. 1999. Quality ratings by experts, and relation with descriptive analysis ratings: A case study with beer. Food Qual. Prefer. 10:59-67.

Haddadin, M. S., R. M. A. Shahin, and R. K. Robinson. 1995. The influence of the casein: Fat ratio in sheep's milk on the chemical composition and sensory properties of Nabulsi cheese. J. Soc. Dairy Technol. 48:71-75.

IDF (International Dairy Federation). 1991. Milk and milk products. Determination of the fat content. IDF Standard 152. IDF, Brussels, Belgium.

Kaminarides, S., E. Rogoti, and H. Mallatou. 2000. Comparison of the characteristics of Halloumi cheese made from ovine milk, caprine milk or mixtures of these milks. Int. J. Dairy Technol. 53:100105.

Kavas, G., G. Oysun, O. Kinik, and H. Uysal. 2004. Effect of some fat replacers on chemical, physical and sensory attributes of low fat white pickled cheese. Food Chem. 88:381-388.

Koca, N., and M. Metin. 2004. Textural, melting and sensory properties of low-fat fresh Kashar cheese produced by using fat replacers. Int. Dairy J. 14:365-373.

Lelievre, J., R. Shaker, and M. Taylor. 1990. The role of homogenization in the manufacture of Halloumi and Mozzarella cheese from recombined milk. J. Soc. Dairy Technol. 43:21-24.
Macfie, H. J., and N. Bratchell. 1989. Designs to balance the effect of order of presentation and first order carry over effects in hall tests. J. Sens. Stud. 4:129-148.

Milci, S., Z. Goncu, Z. Alpkent, and H. Yaygin. 2005. Chemical, microbiological and sensory characterization of Halloumi cheese produced from ovine, capine and bovine milk. Int. Dairy J. 15:625-630.

Moatsou, G., A. Hatzinaki, G. Psathas, and E. Anifantakis. 2004. Detection of caprine casein in ovine Halloumi cheese. Int. Dairy J. $14: 219-226$.

Morien, A., D. Garrison, and N. Keeney Smith. 2008. Range of motion improves after massage in children with burns: A pilot study. J. Bodyw. Mov. Ther. 12:67-71.

Olson, N. F., and M. E. Johnson. 1990. Light cheese products: Characteristics and economics. Food Technol. 10:93-96.

Ozer, B., F. Atasoy, and S. Akin. 2002. Some properties of Urfa cheese (a traditional white-brined Turkish cheese) produced from bovine and ovine milks. Int. Dairy J. 55:94-99.

Papademas, P. 2006. Halloumi cheese. Pages 117-138 in Brined Cheeses. A. Y. Tamime, ed. Blackwell, Oxford, UK.

Papademas, P., J. Norman, and R. Robinson. 2000. Properties of full fat, less fat and reduced fat Halloumi cheeses made from bovine milk. Aust. Dairy Foods 22:30-32.

Papademas, P., and K. Robinson. 2001. The sensory characteristics of different types of Halloumi cheese as perceived by tasters of different ages. Int. J. Dairy Technol. 54:94-99.

Papademas, P., and R. Robinson. 1998. Halloumi cheese: The product and its characteristics. Int. J. Dairy Technol. 51:98-103.

Papademas, P., and R. A. Robinson. 2000. Comparison of the chemical, microbiological and sensory characteristics of bovine and ovine Halloumi cheese. Int. Dairy J. 10:761-768.

Pappa, E., I. Kandarakis, and H. Mallatou. 2007. Effect of different types of milks and cultures on the rheological characteristics of Teleme cheese. J. Food Eng. 79:143-149.

Peryam, D. R., and F. J. Pilgrim. 1957. Hedonic scale method of measuring food preferences. Food Technol. 11:9-14.

Ponce de Leon-Gonzalez, L., W. Wendorff, B. Ingham, D. Thomas, J. Jaeggi, and K. Houck. 2002. Influence of ovine milk in mixture with bovine milk on the quality of reduced fat Muenster-type cheese. J. Dairy Sci. 85:36-42.

Punidadas, P., M. Tung, and J. Feirtag. 2000. Potential use of homogenized whey protein dispersions and process modification for the manufacture of low fat and reduced fat cheddar type cheeses. Int. J. Dairy Technol. 53:45-50.

Robinson, R. K. 1991. Halloumi cheese-The product and its manufacture. Pages 144-158 in Feta and Related Cheeses. R. K. Robinson and A. Y. Tamime, ed. Woodhead, Cambridge, UK.

Rodriguez, J. 1998. Recent advances in the development of low fat cheeses. Trends Food Sci. Technol. 9:249-254.

Romeih, E., A. Michaelidou, C. Biliaderis, and G. Zerfiridis. 2002. Lowfat white-brined cheese made from bovine milk and two commercial fat mimetics: Chemical, physical and sensory attributes. Int. Dairy J. $12: 525-540$.

Schutz, H. G. 1964. A food action rating scale for measuring food acceptance. Paper presented at the 24th Annu. Mtg. Institute of Food Technologists, May 24-28, 1964, Washington, DC.

Shank, F., and L. Carson. 1990. Light dairy products: Regulatory issues. Food Technol. 10:88-92.

Sloan, E. A. 2001. Top 10 trends to watch and work on-3rd Biannual report. Food Technol. 55:38-58.

Theophilou, P., and R. A. Wilbey. 2007. Effects of fat on the properties of Halloumi cheese. Int. J. Dairy Technol. 60:1-4.

Van Horn, L., and N. A. Ernest. 2002. Summary of the science supporting the new National Cholesterol Education Program dietary recommendations: What dietitians should know. J. Am. Diet. Assoc. 101:1148-1154.

Watts, G. F., P. Jackson, V. Burke, and B. Lewis. 1996. Dietary fatty acids and progression of coronary artery disease in men. Am. J. Clin. Nutr. 64:202-209. 